\title{
KETAKUTAN AKAN KEGAGALAN DAN INTENSI PLAGIARISME PADA MAHASISWA
}

\author{
Dhaniar Gusna Fatimah \\ Fakultas Psikologi \\ Universitas YARSI \\ Jl. Letjen. Suprapto, Cempaka Putih \\ Jakarta Pusat 10510, Indonesia \\ e-mail: dhaniargf@gmail.com
}

\begin{abstract}
Previous studies have related plagiarism with several situational factors than internal ones, which are actually interesting to be investigated, such as achievement motivation. The purpose of this study was thus to see the correlation between intention of plagiarism with achievement motivation factors (hope of success and fear of failure). In this study, 210 university students were asked to indicate their responses to the scale of hope of success, fear of failure, and intention of plagiarisme. The result shows a correlation between fear of failure with intention of plagiarism, while insignificant correlation was found between hope of success with intention of plagiarisme. It is concluded that individuals with intention of plagiarisme are more influenced by the feeling of fear of failure.
\end{abstract}

Keywords: failure; intention of plagiarism; students

\begin{abstract}
Abstrak - Beberapa penelitian sebelumnya lebih banyak mengkaitkan plagiarisme dengan faktor situasional padahal terdapat faktor-faktor internal yang menarik untuk dikaji salah satunya faktor pembentuk motivasi berprestasi. Tujuan dari penelitian ini untuk melihat ada atau tidaknya hubungan antara faktor pembentuk motivasi berprestasi (harapan untuk sukses dan ketakutan akan kegagalan) dengan intensi plagiarisme. Penelitian ini merupakan penelitian kuantitatif dengan metode korelasional.Sebanyak 210 sampel diberikan skala hope of success, fear of failure, dan intensi plagiarisme. Hasil dari penelitian menunjukkan adanya hubungan fear of failure dengan intensi plagiarisme. Sebaliknya tidak diperoleh hubungan antara hope of success dengan intensi plagiarisme. Oleh karena itu dapat disimpulkan bahwa individu dengan intensi plagiarisme lebih dipengaruhi oleh perasaan takut akan kegagalan.
\end{abstract}

Kata Kunci: kegagalan; intensi plagiarisme; mahasiswa 


\section{PENDAHULUAN}

\section{Latar Belakang}

Kecurangan akademik merupakan perilaku pencurian ide-ide atau bentuk lainnya dari kepemilikan intelektual (Dobrovska \& Pokorny, 2007). Salah satu bentuk kecurangan akademik adalah plagiarisme. Menurut data dari Direktorat Jenderal Pendidikan Tinggi, tercatat sebanyak 21 perguruan tinggi di Indonesia tersangkut praktik plagiarisme (Wahyuningtyas, 2013). Praktik ini dinilai sebagai cara singkat yang salah dalam menyelesaikan suatu tugas. Studi kasus yang dilakukan oleh Rangkuti (2011) kepada 120 mahasiswa jurusan akuntansi pada salah satu universitas di Jakarta menunjukkan bahwa hampir seluruh mahasiswa pernah melakukan perilaku ketidakjujuran akademik. Salah satu perilaku ketidakjujuran akademik yang paling banyak dilakukan adalah plagiarisme, yaitu menulis ulang (copy-paste) seluruh bagian atau sebagian tulisan orang lain tanpa mencantumkan sumber, atau tidak menggunakan kalimat sendiri (parafrase) dalam menuliskan materi dari internet ke dalam tugas. Suwarjo dkk. (2012) melakukan survei kepada mahasiswa fakultas pendidikan di salah satu universitas di Yogyakarta dan menemukan bahwa terdapat 1.405 frekuensi plagiarisme yang dilakukan oleh mahasiswa dari 181 buah skripsi. Hasilhasil penelitian tersebut menunjukkan adanya praktik plagiarisme yang dilakukan oleh mahasiswa.

Perilaku plagiarisme merupakan pelanggaran moral. Pelanggaran tersebut berdampak kepada penurunan kualitas diri, seperti menjadi semakin malas dalam membuat suatu karya. Gu dan Brooks (dalam Salleh, Ghazali, Awang, \& Sapiai, 2012) juga menyatakan bahwa plagiarisme akan memberikan pengaruh pada lima nilai fundamental yaitu kejujuran, kepercayaan, keadilan, kehormatan (respect), dan tanggung jawab. Individu yang melakukan plagiarisme tentu akan kehilangan kelima nilai fundamental tersebut dari lingkungannya. Selain itu, perilaku ini juga dapat berdampak buruk kepada nama baik institusi.

Perilaku plagiarisme dapat timbul karena adanya niat atau intensi. Beberapa faktor yang mendasari timbulnya intensi tersebut adalah sikap terhadap perilaku, norma subjektif, dan persepsi mengenai pengaturan perilaku (perceived behavioral control) (Stone, Jawahar, \& Kisamore, 2010). Dalam hal ini, sikap terkait dengan keyakinan dan evaluasi individu terhadap suatu perilaku. Kemudian, norma subjektif merupakan keyakinan individu atas harapan orang sekitar mengenai bagaimana individu berperilaku dan terdapat dorongan internal untuk memenuhi harapan tersebut. Faktor ketiga yaitu persepsi mengenai pengaturan perilaku yaitu seberapa sulit bagi individu untuk melakukan suatu perilaku (Ajzen, 2005). 
Parsons dkk. (dalam Mujahidah, 2009) menyatakan bahwa perilaku plagiarisme tidak hanya dilakukan oleh mahasiswa yang berprestasi rendah, tetapi juga dilakukan oleh yang berprestasi tinggi. Hasil penelitian Dordoy (dalam Amstrong, 2008) menyatakan bahwa aspek kesengajaan yang dikarenakan adanya keinginan untuk mendapat nilai atau tingkat yang lebih baik merupakan alasan bagi mahasiswa yang melakukan plagiarisme. Faktor ini juga didukung oleh hasil penelitian Williams, Nathanson, dan Paulhus (2010) yang menemukan bahwa pencapaian tujuan akademik seperti nilai yang tinggi, memenangkan beasiswa, dan menerima penghargaan merupakan motivasi mahasiswa untuk melakukan plagiarisme. Selain itu, ketakutan akan kemampuan menulis yang tidak baik juga dapat menyebabkan mahasiswa mencari hasil karya orang lain yang dinilai lebih baik (Dobrovska \& Pokorny, 2007).

Perilaku plagiarisme biasanya lebih dipengaruhi oleh motivasi individu daripada faktor situasional (Rettinger \& Kramer, dalam Miranda \& Freire, 2011). Dobrovska dan Pokorny (2007) juga menyatakan bahwa adanya faktor-faktor emosi, seperti: sikap terhadap belajar, temperamen, dan kebutuhan berprestasi individu yang dapat berkontribusi dalam perilaku plagiarisme (Dobrovska \& Pokorny, 2007). Pernyataan ini menunjukkan bahwa ada faktor kepribadian yang memengaruhi perilaku plagiarisme. Dalam hal ini, faktor kepribadian yang dapat menjelaskan perilaku plagiarisme adalah motivasi untuk berprestasi (Williams, Nathanson, \& Paulhus, 2010).

Dapat dipahami secara umum bahwa perilaku individu muncul berdasarkan adanya kebutuhan untuk mencapai suatu tujuan. Kebutuhan itu mendorong individu untuk melakukan usaha dalam mencapai tujuan yang lebih baik berdasarkan standar yang ditetapkan oleh masingmasing individu. Refleksi implementasi standar setiap individu dapat menghasilkan konflik internal yang berupa dua kecenderungan, yaitu kecenderungan berharap untuk sukses atau ketakutan akan kegagalan (Royer, 2013). Kedua kecenderungan ini menurut Atkinson menentukan bagaimana individu menyelesaikan suatu tugas, yang menunjukkan apakah individu akan berjuangan untuk meraih kesuksesan atau mengantisipasi kegagalan (Sopah, 2000).

Individu yang mempunyai harapan sukses dalam mengerjakan tugas merupakan individu dengan motivasi berprestasi yang tinggi (Kumar \& Stoody, dalam Olanrewaju, 2010). Individu tersebut mendapatkan kesenangan dari apa yang dikerjakan, karena merasa tertantang untuk mengevaluasi kemampuan dalam diri, sehingga mereka melakukannya dengan sungguh-sungguh dan bertanggung jawab. Sementara itu, individu dengan ketakutan akan kegagalan yang tinggi cenderung mengindikasikan motivasi berprestasi yang rendah (Sopah, 2000). Individu tersebut cenderung tidak yakin dengan kemampuan diri dalam mengerjakan tugas sehingga cenderung memilih pekerjaan yang sangat mudah atau yang paling sulit (Royer, 2013). Kecemasan akan 
kegagalan yang lebih tinggi daripada emosi positif dapat membuat individu memilih untuk mengurangi kecemasannya daripada menghilangkan penyebab kecemasan. Oleh karenanya, individu akan mengurangi usaha untuk mencapai tujuan dan melakukan strategi yang tidak efektif dalam proses mencapai tujuan tersebut (Martin, dkk, dalam De Castella, Byrne, \& Covington, 2012). Royer (2013) menyatakan bahwa salah satu cara untuk mengurangi perasaan takut akan kegagalan yang mungkin dilakukan oleh individu adalah dengan melakukan ketidakjujuran akademik. Perilaku tersebut dinilai sebagai jalan pintas karena individu tidak memerlukan usaha yang lebih untuk mendapatkan kesuksesan.

\section{Harapan untuk Sukses (Hope of Success)}

Kecenderungan untuk sukses memiliki keterkaitan dengan emosi positif dan keyakinan individu untuk sukses (Steinmayr \& Spinath, 2009) sebelum kesuksesan tersebut tercapai (Smith, 2015). Mclelland mengatakan bahwa individu yang mempunyai harapan untuk sukses (hope of success) yang tinggi memperlihatkan adanya kepuasan dan tidak adanya kecemasan terhadap kegagalan dalam mencapai tujuan (dalam Clark, Teevan, \& Ricciuti, 1956). Selain itu, individu tersebut juga lebih termotivasi untuk menguasai suatu tugas, sehingga lebih memilih tujuan-tujuan yang mempunyai tantangan yang sesuai dengan kemampuannya dan berfokus kepada orang-orang yang telah sukses (Pang, Villacorta, Chin, \& Morrison, 2009). Harapan tersebut dipengaruhi oleh dukungan sosial yang diterima oleh individu, keyakinan individu terhadap kemampuannya, dan kontrol individu (Weil, dalam Sembiring \& Fauzia, 2012).

\section{Ketakutan akan Kegagalan (Fear of failure)}

Ketakutan akan kegagalan memiliki keterkaitan dengan emosi negatif dan ketakutan pada situasi pencapaian yang di luar dari kemampuan diri individu tersebut (Steinmayr \& Spinath, 2009), walaupun kegagalan tersebut belum benar-benar terjadi (Smith, 2015). Berkebalikan dengan individu dengan kecenderungan untuk sukses, inidvidu yang takut akan kegagalan merasa cemas dan memiliki harapan yang rendah untuk mencapai kesuksesan, sehingga individu harus menghindari pencitraan yang merugikan dan meningkatkan pencitraan yang berkaitan dengan tujuan yang ingin dicapai (Mclelland, dalam Clark dkk., 1956). Ketakutan akan kegagalan juga dipengaruhi oleh beberapa faktor yaitu suasana dalam kelas, suasana keluarga, dan alam pikiran individu (Winkel, dalam Sah, 2014). 


\section{Intensi Plagiarisme}

Ajzen (2006) mendefinisikan intensi sebagai pertimbangan atas kesiapan individu untuk berperilaku tertentu. Owens dan White (2013) menyatakan bahwa perilaku plagiarisme adalah perilaku menggunakan sebagian atau keseluruhan ide atau kata-kata orang lain tanpa menyebutkan sumbernya secara memadai. Dengan demikian intensi plagiarisme adalah niat individu untuk menggunakan sebagian atau keseluruhan ide atau kata-kata orang lain tanpa pengakuan sumber yang tepat. Pengukuran intensi plagiarisme dalam penelitian ini menggunakan tiga komponen yang disebutkan oleh Ajzen untuk mengukur kecurangan akademik (dalam Stone dkk., 2010) yaitu :

Sikap terhadap perilaku yang jahat (attitude toward misconduct). Sikap terhadap perilaku yang jahat merupakan penilaian individu mengenai perilaku tertentu dengan konsekuensinya, serta bagaimana keyakinan individu terhadap perilaku tersebut. Dalam hal ini, sikap diukur berdasarkan bagaimana individu menilai keinginannya untuk melaporkan tindakan kecurangan serta keyakinannya terhadap kecurangan akademik. Selain itu, sikap yang diukur juga termasuk keyakinan individu mengenai membantu orang lain dalam melakukan kecurangan akademik. Whitley (dalam Harding, Mayhew, Finelli, Carpenter, \& Donald, 2007) mengatakan bahwa murid yang mempunyai sikap positif terhadap perilaku menyontek akan cenderung menyontek.

Norma subjektif (subjective norms). Norma subjektif merupakan persepsi indvidu terhadap penerimaan atau penolakan orang-orang di sekitar atas perilaku yang dilakukan. Secara spesifik, norma subjektif dapat diukur melalui persepsi serta kecurigaan individu mengenai variasi dan frekuensi perilaku kecurangan akademik yang terjadi di sekeliling individu. Whitley (dalam Harding, dkk, 2007) mengatakan bahwa semakin besar persepsi individu bahwa perilaku kecurangan akademik dapat diterima di sekelilingnya, maka inidvidu tersebut akan cenderung melakukan kecurangan akademik tersebut.

Persepsi akan pengaturan perilaku (perceived behavioral control). Persepsi akan pengaturan perilaku merupakan penilaian individu mengenai kemudahan atau kesulitan dalam menampilkan suatu perilaku tertentu. Secara spesifik, hal tersebut merupakan kontrol perilaku yang dipersepsikan melalui efikasi diri individu dan persepsi mengenai mudah atau sulitnya untuk melakukan kecurangan akademik tersebut. Whitley (dalam Harding dkk., 2007) mengatakan bahwa individu yang menilai dirinya berkompeten untuk melakukan kecurangan akademik akan cenderung melakukan kecurangan akademik.

Berdasarkan penjelasan di atas, penelitian ini menjadi penting untuk dilakukan karena penelitian sebelumnya lebih berfokus kepada nilai akademis yang sebenarnya merupakan hasil (output) dari apa yang telah dilakukan oleh individu. Apabila penelitian sebelumnya lebih banyak membuktikan faktor situasional dalam memengaruhi intensi plagiarisme, maka penelitian ini akan menguji faktor internal, khususnya motivasi berprestasi, berdasarkan harapan untuk sukses dan ketakutan akan kegagalan. Dengan demikian, peneliti merasa penting untuk melihat apakah terdapat 
hubungan antara motivasi berprestasi yang berdasarkan harapan untuk sukses dan ketakutan akan kegagalan dengan intensi perilaku plagiarisme pada mahasiswa. Adapun hipotesis penelitian ini yang dibagi menjadi dua. Pertama, terdapat hubungan yang signifikan antara harapan untuk sukses dengan intensi plagiarisme $\left(\mathrm{H}_{\mathrm{A} 1}\right)$. Kedua, terdapat hubungan yang signifikan antara ketakutan akan kegagalan dengan intensi plagiarisme $\left(\mathrm{H}_{\mathrm{A} 2}\right)$.

\section{METODE}

\section{Partisipan}

Partisipan dalam penelitian ini ialah mahasiswa. Adapun karakteristik yang harus dipenuhi yaitu mahasiswa aktif dan pernah melakukan minimal satu perilaku plagiarisme. Dalam penyebaran kuesioner, peneliti memilih mahasiswa yang berkuliah di Jakarta. Alasannya adalah saat ini pengguna internet di Indonesia mencapai 881 juta orang dan 65\% dari total pengguna internet berada di wilayah Jakarta berdasarkan riset dari Asosiasi Penyedia Jasa Internet Indonesia Tahun 2014 (Maulana, 2015). Miranda dan Freire (2011) menyatakan bahwa peningkatan teknologi dan perkembangan internet merupakan hal yang paling memengaruhi individu untuk melakukan kecurangan termasuk di dalamnya adalah perilaku plagiarisme.

\section{Desain}

Penelitian ini merupakan penelitian kuantitatif untuk melihat adanya hubungan antara faktor pembentukan motivasi berprestasi yang terdiri dari harapan untuk sukses dan ketakutan akan kegagalan dengan intensi plagiarisme pada mahasiswa dengan menggunakan teknik analisa korelasi Spearman (Spearman, 2009). Selain itu, penelitian ini menggunakan metode asosiatif korelasional, yaitu metode yang digunakan untuk melihat hubungan antara dua variabel atau lebih (Sugiyono, 2009).

\section{Prosedur}

Proses pengumpulan data dalam penelitian ini adalah dengan memberikan kuesioner kepada partisipan. Dalam menentukan partisipan, peneliti menggunakan accidental sampling yaitu teknik penentuan sampel berdasarkan siapa saja yang kebetulan bertemu dengan peneliti dan dipandang cocok sebagai sumber data (Sugiyono, 2009). Adapun kuesioner yang diberikan terdiri dari dua alat ukur yaitu alat ukur yang mengukur faktor pembentuk motivasi berprestasi dan alat ukur kedua mengukur intensi plagiarisme. Alat ukur faktor pembentuk motivasi berprestasi disusun 
berdasarkan kuesioner yang diadaptasi dari Lang dan Fries (2006), sedangkan alat ukur intensi plagiarisme disusun berdasarkan kuesioner yang dimodifikasi dari Stone dkk. (2010) berdasarkan teori yang direncanakan oleh Ajzen (2005).

Pada alat ukur faktor pembentuk motivasi berprestasi terdapat dua skala yaitu mengukur harapan untuk sukses dan mengukur ketakutan akan kegagalan. Masing-masing variabel dapat diketahui total skor dari masing-masing skala. Semakin tinggi skor, maka variabel yang dimiliki individu semakin tinggi. Adapun intensi plagiarisme juga didapatkan dari total skor skala intensi plagiarisme. Semakin tinggi total skor, maka intensi plagiarisme dalam diri individu semakin tinggi.

Sebelum melakukan adaptasi dan modifikasi alat ukur, peneliti melakukan penerjemahan alat ukur yang dilakukan oleh salah satu dosen di Optima bahasa Inggris Universitas Yarsi dan back translation ke dalam bahasa Inggris. Pada alat ukur intensi plagiarisme, peneliti melakukan beberapa modifikasi pada indikator dan butir. Selanjutnya peneliti melakukan penilaian ahli (expert judgement) oleh ketiga dosen fakultas Psikologi Universitas Yarsi. Setelah itu juga dilakukan uji keterbacaan kepada tiga orang mahasiswa aktif.

Pada pengujian reliabilitas, peneliti melakukan uji alat ukur kepada 50 mahasiswa dengan menggunakan perhitungan Cronbach's Alpha. Bersamaan dengan uji reliabilitas, butir setiap alat ukur dilakukan analisis butir, agar dapat menyaring butir yang memenuhi persyaratan kualitas dengan melihat corrected item-total correlation. Butir yang memenuhi syarat harus berada di atas nilai .2. Hasil uji skala harapan untuk sukses dan ketakutan akan kegagalan memiliki nilai reliabilitas dengan kategori tinggi dengan nilai Cronbach's Alpha .847 dan .745 sehingga tidak terdapat butir yang harus dihapus $(r>.2)$. Sedangkan pada skala intensi plagiarisme $(\alpha=.932)$ terdapat beberapa butir yang memiliki nilai corrected item-total correlation di bawah .2 dan negatif.

Tabel 1.

Contoh Butir Kuesioner

\begin{tabular}{llll}
\hline \multicolumn{1}{c}{ Variabel } & \multicolumn{1}{c}{ Butir yang memenuhi syarat } & Butir yang dihapus \\
\hline Harapan & Saya menyukai situasi yang dapat & - & \\
untuk & menunjukan kemampuan saya dalam & & \\
sukses & melakukan sesuatu. \\
$\begin{array}{l}\text { Ketakutan } \\
\text { akan }\end{array}$ & $\begin{array}{l}\text { Saya takut gagal dalam situasi yang sulit } \\
\text { kegagalan }\end{array}$ & - & \\
\hline
\end{tabular}




\begin{tabular}{lll}
\hline \multicolumn{1}{c}{ Variabel } & \multicolumn{1}{c}{ Butir yang memenuhi syarat } & \multicolumn{1}{c}{ Butir yang dihapus } \\
\hline Intensi & Saya akan melaporkan tindakan plagiat & Menurut saya penjiplakan yang \\
Plagiarisme e & yang dilakukan oleh mahasiswa lain & dilakukan oleh mahasiswa dalam \\
& Teman-teman saya melarang saya untuk & hal akademik penting untuk \\
& melakukanplagiat. & dilaporkan. \\
& Di kampus saya akan sangat mudah bagi & Sangat sulit untuk melakukan \\
& saya untuk melakukan plagiarism & plagiat dan tidak ketahuan \\
& Seberapa ingin anda melakukan plagiat di & Seberapa mungkin anda dapat \\
& kampus? & melakukan plagiat \\
& & \\
\hline
\end{tabular}

\section{Teknik Analisis}

Penelitian asosiatif dalam pengujian hipotesis adalah dengan melihat nilai korelasi antar variabel. Nilai korelasi tersebut merupakan angka yang menunjukkan arah dan kuatnya hubungan antara dua variabel atau lebih. Sebelum dilakukan pengujian hipotesis, maka akan dilakukan uji normalitas data yang diambil dari suatu populasi. Pengujian normalitas data melihat apakah distribusi data yang dilakukan normal atau tidak. Jika uji normalitas data berdistribusi normal, maka teknik statistik yang digunakan adalah teknik statistik parametrik yaitu korelasi Pearson. Sedangkan, jika data tidak berdistribusi normal maka teknik statistik yang digunakan adalah teknik statisik non-parametrik yaitu korelasi Spearman (Nisfiannoor, 2009).

\section{ANALISIS DAN HASIL}

\section{Deskripsi Partisipan}

Jumlah partisipan yang digunakan dalam penelitian ini adalah 210 mahasiswa aktif (45 lakilaki dan 165 perempuan) yang terdaftar di perguruan tinggi di Jakarta dan pernah melakukan minimal satu perilaku plagiarisme. Sebagian besar mahasiswa berusia 18 hingga 20 tahun (63.8\%) dan berada pada semester dua atau tiga $(48 \%)$ dan pernah melakukan perilaku plagiarisme. Pada pengisian aktivitas plagiarisme, individu dapat memilih lebih dari satu pilihan sehingga jumlah respon aktivitas plagiarisme lebih besar dari jumlah sampel. Hasilnya, bentuk plagiarisme yang paling banyak dilakukan oleh mahasiswa yaitu menulis ulang sejumlah kalimat dari beberapa sumber dan menaruhnya dalam susunan yang berbeda $(22 \%)$.

Tabel 2 merangkum berbagai bentuk aktivitas plagiarisme yang pernah dilakukan partisipan. 
Tabel 2.

Gambaran Partisipan

\begin{tabular}{lll}
\hline Aktivitas Plagiarisme & Total & \% \\
\hline $\begin{array}{l}\text { Menulis ulang sejumlah kalimat dari beberapa sumber dan menaruhnya } \\
\text { dalam susunan yang berbeda }\end{array}$ & 142 & $22 \%$ \\
$\begin{array}{l}\text { Menggunakan informasi tanpa menuliskan sumber atau tanda kutipan. } \\
\text { Merumuskan dengan kata-kata sendiri sejumlah kalimat tanpa }\end{array}$ & 99 & $14 \%$ \\
menyatakan sumber & 96 & $13 \%$ \\
$\begin{array}{l}\text { Kerja sama yang dilarang } \\
\text { Melakukan translate pada sejumlah kalimat tanpa menuliskan }\end{array}$ & 89 & $12 \%$ \\
$\begin{array}{l}\text { sumbernya. } \\
\text { Mencantumkan sumber tetapi tidak memberi tanda kutipan. }\end{array}$ & 89 & $12 \%$ \\
$\begin{array}{l}\text { Menggunakan tanda kutipan tapi tidak menuliskan sumber. } \\
\text { Menggunakan informasi tetapi salah mencantumkan sumber atau } \\
\text { memalsukan sumber. }\end{array}$ & 70 & $11 \%$ \\
\hline
\end{tabular}

\section{Uji Normalitas Data}

Pada penelitian ini uji normalitas menggunakan Kolmogorov-Smirnov Test. Adapun syarat sebuah data berdistribusi normal adalah nilai signifikan di atas .05 ( $p>.05)$ (Nisfiannoor, 2009).

Berdasarkan analisis uji normalitas, skala harapan untuk sukses, skala ketakutan akan kegagalan, dan skala intensi plagiarisme tidak berdistribusi normal. Oleh karena itu, uji hipotesis data dilakukan dengan teknik stastistik non-parametrik.

\section{Uji Beda}

Pada penelitian ini dilakukan uji beda untuk melihat apakah terdapat perbedaan intensi plagiarism yang dimiliki individu berdasarkan usia, semester, dan jenis kelamin. Uji beda ini menggunakan statistik parametrik yaitu Chi-Square untuk usia dan semester, sedangkan untuk jenis kelamin menggunakan Mann-Whitney $U$. Hasil menunjukkan bahwa tidak terdapatnya perbedaan intensi plagiarisme individu berdasarkan usia, jenis kelamin, dan semester seperti tergambar pada tabel berikut:

Tabel 3.

Hasil Uji Beda

\begin{tabular}{|c|c|c|c|c|}
\hline \multicolumn{2}{|c|}{ Variabel } & Mean & Nilai Uji beda & Sig. \\
\hline Usia & $\begin{array}{c}18-20 \\
21-23 \\
<23\end{array}$ & $\begin{array}{l}65.94 \\
68.09 \\
69.67\end{array}$ & 0.226 & .893 \\
\hline Semester & $\begin{array}{l}2-3 \\
4-5 \\
>6\end{array}$ & $\begin{array}{l}64.68 \\
70.06 \\
67.57\end{array}$ & 3.610 & .164 \\
\hline Jenis kelamin & $\begin{array}{l}\text { Laki-laki } \\
\text { Perempuan }\end{array}$ & $\begin{array}{l}71.38 \\
65.53\end{array}$ & -1.917 & .055 \\
\hline
\end{tabular}

Keterangan: DV = Intensi plagiarisme 
Berdasarkan nilai signifikansi pada ketiga variabel, tidak ditemukan adanya perbedaan intensi plagiarisme mahasiswa berdasarkan usia, semester, dan jenis kelamin.

\section{Uji Hipotesis}

Hasil pengujian Spearman's rho menunjukkan bahwa ketakutan akan kegagalan mempunyai hubungan yang signifikan dengan intensi plagiarism $\left(r_{\mathrm{s}}=.158 ; p=.022\right)$. Hal ini berarti semakin tinggi ketakutan akan kegagalan yang dirasakan individu, maka semakin tinggi juga intensi untuk melakukan plagiarisme, begitu pula sebaliknya. Di sisi lain, harapan untuk sukses ditemukan tidak berkorelasi terhadap intensi plagiarism $\left(r_{s}=-.083 ; p=.158\right)$.

\section{DISKUSI}

Hasil penelitian ini menunjukkan adanya hubungan antara ketakutan akan kegagalan dengan intensi plagiarism, yang dapat mendukung penelitian sebelumnya di mana ketakutan akan kegagalan dinilai sebagai salah satu sistem dari keyakinan dalam diri individu yang dapat memprediksi kemungkinan individu melakukan plagiarisme (Barnett dalam Wilkinson, 2009). Siaputra (2013) juga menyatakan bahwa salah satu dimensi motivasi berprestasi yaitu ketakutan akan kegagalan, yang merupakan indikator adanya kenaikan terhadap perilaku plagiarisme. Studi yang dilakukan oleh Sheard, Markham, dan Dick (dalam Sheard \& Dick, 2012) pada mahasiswa teknik informatika juga membuktikan bahwa tekanan terhadap waktu dan ketakutan akan kegagalan merupakan faktor utama yang memengaruhi perilaku plagiarisme.

Individu dengan ketakutan akan kegagalan yang lebih tinggi mengindikasikan adanya motivasi berprestasi yang rendah (Royer, 2013). Indikasi ini dipengaruhi oleh faktor intrinsik dan ekstrinsik individu. Faktor dalam diri berupa rasa tidak puas, cemas, dan malu jika terjadi kegagalan akan memengaruhi ketakutan akan kegagalan yang dirasakan individu. Selain faktor dalam diri, harapan atau standar tinggi yang ditetapkan lingkungan, terutama orangtua, juga dapat memengaruhi bagaimana individu mendefinisikan dan mempersepsikan kegagalan yang terjadi pada dirinya (McGregor \& Elliot, 2005). Begitu pula dengan insentif yang didapatkan dari lingkungan yaitu berupa penghargaan, akan meningkatkan kemungkinan individu menggunakan cara-cara singkat untuk mengurangi kecemasannya dalam mencapai suatu tujuan (Adibah, 2012). Hal-hal yang memengaruhi ketakutan akan kegagalan tersebut membuat individu berusaha untuk tidak mengambil risiko yang besar, tetapi tetap memberikan standar yang tinggi agar mendapatkan hasil yang sempurna, sehingga kemungkinan melakukan plagiarisme semakin besar (Royer, 2013). 
Adapun hal-hal lain yang dapat memengaruhi faktor ketakutan akan kegagalan, tetapi tidak dipertanyakan dalam penelitian ini, sehingga tidak dapat memberikan gambaran lebih jelas mengenai faktor yang memengaruhi ketakutan akan kegagalan, serta yang berkaitan dengan intensi plagiarisme.

Sebaliknya, penelitian ini menunjukkan bahwa tidak terdapat hubungan yang signifikan antara harapan untuk sukses dengan intensi plagiarisme mahasiswa. Secara tidak langsung hasil penelitian ini tidak mendukung penelitian sebelumnya bahwa harapan untuk sukses berkaitan dengan ciri-ciri individu dengan motivasi berprestasi akan mempunyai hubungan negatif yang signifikan dengan perilaku kecurangan akademik termasuk di dalamnya perilaku plagiarisme (Olanrewaju, 2010).

Berdasarkan faktor demografis yaitu jenis kelamin, usia, dan semester tidak ditemukan adanya perbedaan yang signifikan. Hasil uji beda ini mendukung penelitian sebelumnya oleh Wilkinson (2009) yang menyatakan bahwa tidak ada penemuan yang konsisten terkait dengan faktor usia, jenis kelamin, tingkat akademik yang berkaitan dengan perilaku penyimpangan akademik.

\section{SIMPULAN DAN SARAN}

\section{Simpulan}

Hasil penelitian ini menunjukkan adanya hubungan yang positif antara ketakutan akan kegagalan dengan intensi plagiarisme pada mahasiswa, sehingga diartikan bahwa semakin tinggi ketakutan akan kegagalan maka semakin besar juga niat individu untuk melakukan plagiarisme. Selain itu, hasil penelitian juga menunjukkan tidak adanya hubungan antara harapan untuk sukses dengan intensi plagiarisme pada mahasiswa.

\section{Saran Teoretis}

Beberapa saran teoretis untuk penelitian selanjutnya adalah sebagai berikut. Pertama, peneliti selanjutnya dapat menambahkan faktor situasional agar dapat melihat perbandingan secara langsung dengan faktor pembentuk motivasi berprestasi dalam hubungannya dengan intensi plagiarisme. Kedua, peneliti selanjutnya dapat mengukur faktor-faktor yang memengaruhi ketakutan akan kegagalan seperti harapan orangtua agar memberikan gambaran yang jelas mengenai pengaruh terhadap ketakutan akan kegagalan yang berkaitan dengan intensi plagiarisme. Ketiga, peneliti selanjutnya dapat menambah variabel lain yaitu lokus kontrol (locus of control) 
untuk melihat hubungannya terhadap faktor pembentuk motivasi berprestasi dalam memengaruhi intensi plagiarisme. Keempat, peneliti selanjutnya dapat menambah data demografis penelitian terkait keterangan institusi negeri atau swasta agar memberikan gambaran detil mengenai profil data subjek.

\section{Saran Praktis}

Hasil penelitian menunjukkan bahwa intensi melakukan plagiarisme berhubungan dengan dimensi pembentuk motivasi berprestasi ketakutan akan kegagalan. Semakin individu merasa takut akan kegagalan, maka akan semakin tinggi kecenderungannya untuk melakukan plagiarisme. Oleh karena itu, untuk mengurangi intensi melakukan plagiarisme perlu dilakukan intervensi untuk mengurangi ketakutan akan kegagalan pada mahasiswa. Terdapat beberapa faktor yang memengaruhi ketakutan akan kegagalan, tetapi tidak diteliti pada penelitian ini seperti rasa tidak puas, kecemasan, dan standar atau harapan orangtua yang tinggi. Dengan demikian, praktisi yang ingin mengurangi intensi plagiarisme dengan melakukan intervensi terhadap ketakutan akan kegagalan, perlu melakukan analisis mengenai faktor-faktor yang berperan dalam pembentukan ketakutan akan kegagalan tersebut.

\section{REFERENSI}

Adibah, P. (2012). Hubungan antara motivasi berprestasi dengan fear of success pada wanita bekerja dewasa muda (Naskah tidak dipublikasikan). Jurnal Fakultas Psikologi Universitas Gunadarma, Indonesia.

Ajzen, I. (2005). Attitudes, personality, and behavior (2 ${ }^{\text {nd }}$ ed.). New York, NY: Open University Press.

Ajzen, I. (2006). Constructing a tpb questionnaire: Conceptual and methodological considerations. Ditemu kembali dari http://people.umass.edu/aizen/pdf/tpb.measurement.pdf

Armstrong, L. (2008). Final year undergraduate student plagiarism: Academic staff and student perceptions. Autumn, 7(3), 16-20.

Atkinson, J., \& Feather, N. (1966). A theory of achievement motivation. New York, NY: Robert E. Krieger.

Clark, R. A., Teevan, R., \& Ricciuti, H. N. (1956). Hope of success and fear of failure as aspects of need for achievement. The Journal of Abnormal and Social Psychology, 53(2), 182-186. 
Dobrovska, D., \& Pokorny, A. (2007). Avoiding plagiarism and collusion. Naskah dipresentasikan pada International Conference on Engineering Education. Ditemu kembali dari http://icee2007.dei.uc.pt/proceedings/papers/112.pdf

De Castella, K., Byrne, D., \& Covington, M. (2013). Unmotivated or motivated to fail? A crosscultural study of achievement motivation, fear of failure, and student disengagement. Journal of Educational Psychology, 105(3), 861-880.

Harding, T. S., Mayhew, M. J., Finelli, C. J., \& Carpenter, D. D. (2007). The theory of planned behavior as a model of academic dishonesty in engineering and humanities undergraduates. Ethics \& Behavior, 17, 255-279.

Lang, J. W. B., \& Fries, S. (2006). A revised 10-item version of the achievement motivation scale: Psychometric properties in german-speaking samples. European Journal of Psychological Assessment, 22, 216-224.

Maulana, A. (2015). Jumlah pengguna internet Indonesia capai 88,1 juta. Liputan 6. Ditemu kembali dari http://tekno.liputan6.com/read/2197413/jumlah-pengguna-internet-capai-881juta.

McGregor, H., \& Elliot, A. J. (2005). The shame of failure: Examining the link between fear of failure and shame. Personality and Social Psychology Bulletin, 31(2), 218-231.

Miranda, S. M., \& Freire, C. (2011). Academic dishonesty-Understanding how undergraduate students think and act. ISATT 2011 Conference. University of Minho, Braga, Portugal. Braga, Portugal: University of Minho.

Mujahidah. (2009). Perilaku menyontek laki-laki dan perempuan: Studi meta analisis. Jurnal Psikologi, 2(2), 177-199.

Nisfiannoor, M. (2009). Pendekatan statistikamodern untuk ilmu sosial. Jakarta: Salemba Humanika.

Olanrewaju, A. S. (2010). Correlation between academic cheating behavior and achievement motivation. Nature and Science, 8(12), 130-134.

Owens, C., \& White, F. (2010). A 5-year systemic strategy to reduce plagiarisme among first-year psychology university students. Australian Journal of Psychology, 65, 14-21.

Pang, J. S., Villacorta, M. A., Chin, Y. S., \& Morrison, F. J. (2009). Achievement motivation in the social context: Implicit and explicit hope of success and fear of failure predict memory for and liking of successful and unsuccessful peer. Journal of Research in Personality, 43, 1040-1052. 
Rangkuti, A. A. (2011). Academic cheating behaviour of accounting students: A case study in Jakarta State University. Educational integrity: Culture and values. Proceedings 5th Asia Pacific Conference on Educational Integrity (pp. 105-109). Perth: Asia Pacific Conference of Educational Integrity.

Royer, S. C. (2013). Faculty and student perceptions of academic cheating and the influence of achievement motivation with online and face-to-face learning environments. UNLV Theses, Dissertations, Professional Papers, and Capstones, 2022.

Sah, M. M. (2014). Hubungan locus of control dan ketakutan akan kegagalan dengan perilaku menyontek pada siswa (Naskah tidak dipublikasikan). Universitas Muhammadiyah Surakarta, Indonesia.

Salleh, M., Ghazali, S., Awang, Z., \& Sapiai, S. (2012). The effect of plagiarisme on the corporate image in the higher education: An extended tpb model. International Journal of Social Science and Humanity, 2(4), 340-343.

Sembiring, E. A., \& Fauzia, R. (2012). Harapan akan kesuksesan perkawinan pada individu yang melakukan perkawinan semarga pada Suku Batak. Predicara, 1(2).

Sheard, J., \& Dick, M. (2012). Directions and dimensions in managing cheating and plagiarisme of IT students. Proceedings of Fourteenth Australasian Computing Education, Melbourne, Australia, 123, 177-185.

Siaputra, I. B. (2013). The 4PA of plagiarisme: A psycho-academic profile of plagiarists. International Journal for Educational Integrity, 9(2), 50-59.

Smith, R. L., (2015). A contextual measure of achievement motivation: Significance for research in Counseling. Ideas and Research You Use: VISITAS 2015.

Sopah, D. (2000). Pengaruh model pembelajaran dan motivasi berprestasi terhadap hasil belajar. Jurnal Pendidikan dan Kebudayaan, 5(22), 121-127.

Steinmayr, R., \& Spinath, B. (2009). The importance of motivation as a predictor of school achievement. Learning and Individual Differences, 19, 80-90.

Stone, T., Jawahar, I. M., \& Kisamore, J. (2010). Predicting misconduct inventions and behavior using the theory of planned behavior and personality. Basic and Applied Social Psychology, $32,33-45$.

Sugiyono. (2009). Statistika untuk penelitian. Bandung: Alfabeta.

Suwarjo, Sugiyatno, Astuti, B., Eliasa, E. I., Tjiptasari, Ratri, N., Utami, N. H. S., Astriwi, C., \& Mayasari, D. (2012). Identifikasi bentuk plagiat pada skripsi mahasiswa fakultas ilmu pendidikan universitas negeri Yogyakarta (Naskah tidak dipublikasikan). Universitas Negeri Yogyakarta, Indonesia. 
Wahyuningtyas, I. (2013). Hubungan orientasi tujuan dengan motivasi berprestasi pada mahasiswa. Educational Psychology Journal, 2(1), 22-29.

Wilkinson, J. (2009). Staff and student of plagiarisme and cheating. International Journal of Teaching And Learning In Higher Education, 20(2), 98-105.

Williams, K., Nathanson, C., \& Paulhus, D. (2010). Identifying and profiling scholastic cheaters: Their personality, cognitive ability, and motivation. Journal of Experimental Psychology, 16(3), 293-307. 